\title{
DINÂMICAS SOCIOLINGUÍSTICAS E CULTURAIS DE INCLUSÃO/EXCLUSÃO DE ALUNOS DESCENDENTES DE IMIGRANTES RUSSOS NO SUL DO BRASIL
}

\author{
Maria Inêz Probst Lucena* \\ Universidade Federal de Santa Catarina \\ Centro de Comunicação e Expressão \\ Florianópolis, SC, Brasil
}

\section{Bianca Campos ${ }^{*}$ \\ Secretaria de Estado da Educação de Santa Catarina Centro de Educação de Jovens e Adultos \\ Florianópolis, SC, Brasil}

\begin{abstract}
Resumo: A partir de uma etnografia escolar, com base em dados gerados de observação participante, entrevistas, diários de campo e análise documental, este estudo foca no modo como os alunos descendentes de imigrantes russos de uma cidade do sul do Brasil lidam com fronteiras linguísticas e dinâmicas socioculturais de inclusão/exclusão na escola. $O$ principal objetivo é mostrar como fronteiras linguísticas e socioculturais aparecem nas falas dos participantes em cenário escolar. A análise dos dados mostra que diferentes perspectivas aparecem. Professores, alunos e equipe diretiva posicionam-se de modos diferentes em relação às fronteiras que ora são reafirmadas, ora são flexibilizadas. Dependendo da situação e do interlocutor, tais fronteiras podem se tornar mais ou menos visiveis, apontando para um processo sociopolítico de inclusão em desenvolvimento naquele contexto específico.

Palavras-chave: Multilinguismo. Fronteiras linguísticas. Fronteiras culturais. Imigrantes russos. Minorias.
\end{abstract}

1 INTRODUÇÃO

Neste estudo, descrevemos algumas características de um cenário marcado pelo multilinguismo, pela interculturalidade e pela mobilidade sociolinguística, a partir da etnografia escolar (ERICKSON, 1990), perspectiva teórico-metodológica que nos tem permitido contemplar formas de comunicação em áreas rurais, espaços ainda pouco considerados na agenda de pesquisa sobre globalização (WANG et al., 2014, p. 25). São focalizados alunos de uma escola pública estadual do interior do Estado do Paraná, descendentes de imigrantes russos chegados ao Brasil no final da década de 1950. Nosso principal objetivo neste artigo é mostrar como as fronteiras linguísticas e culturais aparecem nas falas desses participantes em cenário escolar.

\footnotetext{
* Docente do Programa de Pós-graduação em Linguística da UFSC. ORCID: <http://orcid.org/0000-00017579-5758>. E-mail: lucena.inez@gmail.com

** ORCID: <http://orcid.org/0000-0001-7451-132X>. E-mail: bianca.prs@gmail.com. 
Temos como premissa que a legitimidade da língua e cultura de grupos e de comunidades é reconhecida de acordo com a dinâmica das trocas culturais e econômicas do passado e do presente que importam para o cenário em que vivem, implicando processos de inclusão/exclusão de indivíduos (HELLER, 2003). Ou seja, práticas linguísticas e identitárias, a cultura e o conhecimento dos falantes podem variar de valor, de acordo com parâmetros de adequação e legitimidade de usos da língua e da cultura no tempo/espaço em que estão constituídos (SIGNORINI, 2008). Devido às ideologias linguísticas, "avaliações de cunho moral e político sobre estrutura e uso linguístico passam a garantir o sentido e a legitimidade dos padrões usuais de hierarquização de formas e usos que também servem de parâmetro para a inclusão/exclusão dos falantes em redes, práticas e instituições" (SIGNORINI, 2008, p. 119). Na regulamentação dos usos linguísticos, na disputa de natureza política e ideológica por grupos e indivíduos diferentemente posicionados em estruturas e redes sociais de poder e autoridade, participantes em instituições escolares em que estudam minorias linguísticas vão desenvolvendo meios de viverem e negociarem suas experiências interculturais.

A pesquisa etnográfica aqui discutida foi realizada por uma das autoras durante um semestre, no ano de 2014 , como parte de sua pesquisa de mestrado ${ }^{1}$. A pesquisa original objetivou investigar as práticas de linguagem dos alunos descendentes de imigrantes russos nas aulas de inglês, na condição de grupo etnolinguístico minoritário na escola (CAMPOS, 2015).

Os dados que constituem o corpus de referência para o presente artigo foram gerados, majoritariamente em contexto escolar, a partir de registros de observação participante, entrevistas, documentos, participação em reuniões pedagógicas e em encontros com membros da comunidade ${ }^{2}$ (CAMPOS, 2015), nos moldes do que chamamos etnografia escolar ou etnografia da linguagem (LUCENA, 2015). Entendemos que linguagem e mundo social "são mutualmente moldados" e que "uma análise detalhada do uso da linguagem e da cultura situada pode fornecer insights fundamentais e distintos para os mecanismos e dinâmicas da produção social e cultural na atividade cotidiana" (RAMPTON et al., 2004, p. 2).

Da mesma forma que Garcez e Schulz (2015), desenvolvemos a etnografia da linguagem, cuja base vem da etnografia da comunicação de Hymes (1996) e buscamos, com Erickson (1990), entender a ecologia da vida escolar conjuntamente com os interlocutores da instituição educacional. Os significados das ações que discutimos na análise aqui apresentada buscam a perspectiva êmica e procuram revelar o ponto de vista dos participantes, especialmente dos alunos e das alunas descendentes de russos, da equipe diretiva e de professores do contexto em estudo. A discussão de aspectos relacionados a linguagem, cultura e identidade na instituição escolar construída com base na etnografia escolar, permite-nos entender, portanto, conforme destaca Kleiman, o modo

\footnotetext{
${ }^{1}$ Pesquisa aprovada pelo Comitê de Ética e Pesquisa com Seres Humanos (CEPSH), da UFSC, processo número: 36210214.9.000.0115, parecer número: 879513.

2 Pesquisa aprovada pelo Comitê de Ética e Pesquisa com Seres Humanos (CEPSH), da UFSC, processo, número: 36210214.9.000.0115, parecer, número: 879513.
} 
que a produção de significados sociais contribui para reafirmar ou rejeitar identidades culturais e linguísticas (KLEIMAN, 1998, p. 281) ${ }^{3}$.

Na próxima seção, apresentamos o cenário da pesquisa, a colônia dos imigrantes e a escola, e discutimos como as fronteiras linguísticas e culturais são constituídas e as dinâmicas sociopolíticas de inclusão/exclusão são acionadas naquele cenário.

\section{A "COLÔNIA DE RUSSOS"4 E O COLÉGIO BENJAMIN 2.1 A COLÔNIA}

Os imigrantes russos da comunidade em estudo chegaram no Brasil em 1959. A comunidade encontra-se na zona rural, no estado do Paraná, distante cerca de $100 \mathrm{~km}$ da capital, Curitiba, em uma região sem apelo turístico, cuja principal fonte de renda é a agricultura. A economia local da cidade desenvolveu-se em torno de uma estratificação étnica, com os brasileiros como proprietários de terra, firmando-se como os patrões, e os russos como trabalhadores e empregados. Na colônia, hoje, convivem apenas cerca de quarenta moradores, que seguem ainda o calendário bizantino, com contagem dos anos e dias diferente do calendário gregoriano, adotado oficialmente na maioria dos países, incluindo o Brasil.

A igreja e a escola exerceram e exercem influentes funções como agentes de reprodução social e cultural naquele espaço. O pastor da igreja ortodoxa rege e comanda, com certo rigor (NOTA DE CAMPO, 24/01/2014), as regras que a comunidade deve seguir e preocupa-se, apoiado pelos mais velhos, especialmente com a valorização das práticas identitárias daquela minoria etnolinguística. É o que aponta o aluno Pedro quando é questionado pela pesquisadora Bianca sobre sua alimentação na escola:

\footnotetext{
Bianca: Você costuma comer o lanche oferecido no colégio?

Pedro: hum ... eu já comi:: ((sorrindo)),... mas não pode. Tem que rezar antes de comer ... e depois tem que pedir perdão na Igreja. A Igreja perdoa ... mas você tem que ficar três semanas sem poder rezar na Igreja ... Depois dessas três semanas, você pode voltar! (ENTREVISTA, 25/10/2014).
}

As missas são realizadas em língua russa, incluindo a leitura da Bíblia, escrita em russo. As crianças são alfabetizadas nessa língua por seus pais; somente perto da idade escolar elas começam a aprender o Português. Sofia, moradora da Colônia, mãe de três crianças em idade escolar, relata que geralmente é questionada sobre o ensino de línguas de seus filhos. Segundo ela: “Tem gente que diz: Quando as crianças são pequenas, por

\footnotetext{
${ }^{3}$ Segundo Kleiman, as questões relativas à identidade são tangenciadas por problemas sociais estruturais, sendo que, em sociedades desiguais a preservação de identidades de minorias está em risco constante (KLEIMAN, 1998, p. 268). Em suas palavras: "o ensino de língua materna, quando esta é entendida com a língua-mãe do grupo dominante, pode ser um importante instrumento do currículo tanto para introduzir os valores e conhecimentos que a sociedade considera necessários e relevantes para todos os seus membros bem como para acelerar o processo de assimilação das minorias." (KLEIMAN, 1998, p. 269).

${ }^{4}$ Designação utilizada em placas de sinalização, indicando a localização da comunidade, dividida em três pequenas colônias.
} 
que vocês ensinam elas em russo? Como elas vão para a escola?" (CONVERSA INFORMAL, 19/01/2014). Conforme ela explica, há uma preocupação e curiosidade por parte de moradores não descendentes de russos em saber como as crianças vão, mais tarde, se adaptar à escola, tendo sido ensinados somente em russo até a idade escolar (NOTA DE CAMPO, 19/01/2014).

\subsection{COLÉGIO}

O contexto em que foi desenvolvida a pesquisa é uma escola pública estadual, chamada aqui de Colégio Benjamin ${ }^{5}$. Esse colégio atendia, na época da pesquisa, 501 estudantes, dentre os quais 16 eram descendentes de russo, em idade entre 13 e 17 anos. Constituíam os repertórios linguísticos desses alunos o português e o russo. No caso de uma única aluna, também o inglês e o espanhol.

As práticas culturais particulares, tais como o uso de roupas típicas ${ }^{6}$ no espaço escolar, a especificidade da culinária, as práticas religiosas do catolicismo ortodoxo, bem como o uso do calendário bizantino, constituem o cotidiano dos alunos filhos de imigrantes. No entanto, como destaca Bloommaert (2010, p. 47), "algumas formas de semioses são sistematicamente percebidas como valiosas, outras como menos valiosas, e algumas não são levadas em conta, absolutamente", embora todas estejam sujeitas a regras de acesso e regulação assim como circulação. A observação situada das práticas contribuiu para o entendimento desses processos escalares no Colégio Benjamin e em discursos produzidos fora da escola, como mostramos a seguir.

\section{DINÂMICAS SOCIOLINGUISTICAS E CULTURAIS DE INCLUSÃO/EXCLUSÃO 3.1 REFERÊNCIAS AO GRUPO MINORITÁRIO EM DISCURSOS PRODUZIDOS FORA DA ESCOLA}

Segundo Waldmann, historiador que escreveu sobre a imigração russa na região, os membros da colônia evitam usar pratos, comidas e bebidas que não sejam deles, evitam conversar com estranhos e proíbem a televisão por receio da influência que ela pode ter sobre os jovens (WALDMANN, 1992, p.55). As roupas, confeccionadas pelas mulheres da colônia, são produzidas a partir da seda colorida e enfeitadas com bordados feitos a mão. Os homens usam calças e túnicas, chamadas de "rubaka" (WALDMANN, 1992, p. 43). Ainda, segundo o autor, cabe ao pastor a realização de missas, casamentos, batizados e celebrações de dias santos. As missas acontecem na madrugada de todo domingo e têm longa duração: têm início às 3h00 da madrugada e se alongam até as 7 h00 ou 8 h00 da manhã. O tempo é preenchido com a leitura da Bíblia e cantos religiosos. Participam da missa todos os da comunidade, inclusive as crianças (WALDMANN,1992, p. 65).

\footnotetext{
${ }^{5}$ O nome Colégio Benjamin é fictício, para preservar a identidade da escola e dos informantes da pesquisa, e se refere a uma escola básica estadual localizada na zona rural do estado do Paraná, a cerca de 100 km de Curitiba.

${ }^{6}$ As mulheres usam vestidos longos de mangas compridas e os homens, calça e camisa de manga longa (Rubaka), com um cordão amarrado na cintura, que, segundo eles, serve para separar a parte limpa da parte suja do corpo.
} 
Num artigo proveniente de um jornal online, a comunidade russa é descrita por um conhecido jornalista da região como

uma comunidade que, em pleno século 21, mantém costumes e trajes do século 19. [...] Todos são descendentes de russos e entre eles só falam nesse idioma. O primeiro idioma ensinado é o russo. As crianças só aprendem o português na escola. A religião é o catolicismo ortodoxo e a igreja da colônia é repleta de ícones religiosos. E não só no idioma que [a colônia] se diferencia. (MURÁ, 2016, n. p.).

Na sequência, o autor fala ainda da diferença da contagem dos anos pelos membros da colônia, da ortodoxia, da proibição de comer com pessoas que não sejam ortodoxas, do fato de os trajes serem confeccionados pela própria comunidade, do uso de lenços na cabeça pelas mulheres, do uso das tranças no cabelo pelas solteiras e do uso do cordão amarrado na cintura pelos homens. Ao final de sua análise e descrição, considera as agruras dos russos que, após fugirem da revolução russa, tentaram refazer suas vidas na China, sem sucesso, encontrando, segundo ele, no sul do Brasil "a paz que tanto procuraram" (MURÁ, 2016, n. p.). Na descrição, os imigrantes são vistos como pessoas que vivem seu cotidiano conforme os moldes de dois séculos atrás, época em que pessoas viviam com pouquíssimos direitos políticos e sociais, além de enfrentarem escassez de recursos para suprir as necessidades básicas.

Diferentemente de Waldmann, as marcas do passado colonial e os costumes tradicionais, presentes no cotidiano da comunidade russa parecem trazer desconcerto para o jornalista, que interpreta a vida contemporânea dos moradores da colônia como a de um povo que vive "no século 19" (MURÁ, 2016).

Um contraponto interessante às descrições de Murá está nos estudos de Heller (2003) sobre minorias etnolinguísticas, geralmente marginalizadas por processos econômicos e políticos, que passam a ser valorizadas devido ao fato da economia globalizada estar centrada na comunicação multilíngue (HELLER, 2003). Com base em pesquisas etnográficas em áreas francófanas do Canadá, Heller discute como essa nova economia resultou na comodificação de língua e identidade, produzindo "novas formas de competição e de seleção social" (HELLER, 2003, p. 474). Ela aponta que novas formas de comodificação de língua e identidade estão se desenvolvendo de acordo com processos que se desenrolam em áreas econômicas diversas e nos chama a atenção para a importância de entender a "economia política dos recursos linguísticos e culturais" (HELLER, 2003, p. 476) e os modos como estes recursos (e o valor atribuído a eles) estão atrelados às condições políticas e econômicas situadas.

Podemos encontrar também espaços retratados em pesquisas no Brasil (FRITZEN; NAZARO; SIEVES, 2014; DALLA VECHIA, 2018), que exemplificam a valorização de recursos linguísticos e culturais locais e nos quais essa nova economia está centrada na comunicação multilíngue. Conforme demonstram Fritzen, Nazaro e Sieves para o caso específico de comunidades de descendentes de imigrantes alemães,

\footnotetext{
nas áreas rurais do país, especialmente na região sul, pode-se constatar sua presença [a língua alemã] como língua de herança, além de outras manifestações culturais relacionadas à "germanidade" em muitas esferas da atividade humana. (FRITZEN; NAZARO; SIEVES, 2014, p. 84).
} 
Também Dalla Vechia (2018) discute o modo como uma comunidade de suábios no sul do Brasil, comumente conhecida como "a colônia de alemães", definida pela autora como um espaço "sociolinguisticamente complexo de origem germânico-suábio" (DALLA VECCHIA, 2018, p. 11) tem-se tornado

\begin{abstract}
famosa pelas iguarias típicas da culinária germânica [...] pelo avanço econômico da região baseado na agricultura e pela atuação da cooperativa local - uma das maiores cooperativas do Paraná e a maior maltaria da América Latina -, e pelas práticas de linguagem muito características da região - o uso do alemão. (DALLA VECHIA, 2018, p. 12).
\end{abstract}

Nesses dois estudos, trazidos aqui como exemplos, podemos entender como a identidade alemã e suábia, que nas comunidades têm legitimidade ou, na palavras de Heller, apresentam um "marketing de autenticidade" (HELLER, 2003, 474), possuem valor econômico e podem redefinir novas formas de relação entre identidade e linguagem.

No espaço da comunidade alemã, retratado por Dalla Vechia, por exemplo, aparece a diversidade do repertório linguístico dos alunos e a participação dos alunos em sala de aula, que, segundo a autora é "construída com base na alternância de línguas" (DALLA VECHIA, 2018, p. 161). De todo modo, importa enfatizar que, embora o falante de suábio tenha legitimidade local, Dalla Vechia mostra que o valor dessa língua minoritária é reconhecido na comunidade pelo fato de o suábio constituir-se como "o caminho para a identidade hegemônica alemã" (DALLA VECHIA, 2018, p. 163). Assim, além do português, que, também "tem valor no mercado local” (DALLA VECHIA, 2018, p. 164), igualmente o suábio desfruta de legitimidade e autenticidade local, ainda que o prestígio local dessa língua minoritária perca valor na medida que a pretensão de seu uso seja para o mercado linguístico translocal (DALLA VECHIA, 2018).

No cenário da "colônia dos russos", aqui focalizada, o que se tem é um espaço que, ao contrário das comunidades franco-canadenses e alemãs mencionadas acima, é pouco prestigiado localmente ou valorizado pelos processos da globalização. Enquanto minoria etnolinguística, os russos e seus descendentes não ascenderam a aberturas e oportunidades trazidas por esses processos e, portanto, não exercem, naquele espaço em que vivem, o mesmo protagonismo das comunidades nos estudos supracitados. Sem uma língua e uma identidade comodificáveis, os descendentes de imigrantes russos não trazem àquele cenário interesses econômicos ou qualquer apelo turístico. Ou seja, a economia política local não está relacionada com os recursos linguísticos e culturais desses imigrantes, o que não contribui para que seu repertório multilíngue seja valorizado. Sendo assim, o capital cultural desses imigrantes não está implicado diretamente com atividades associadas a mobilidades geradas pela globalização, de modo que consigam despertar o interesse do estado e da comunidade do entorno. A língua e cultura russas não são, portanto, tomadas como recursos de valor e tampouco caracterizadas como itens culturais com valor de mercado. 


\title{
3.2 REFERÊNCIAS À DIVERSIDADE NAS ORIENTAÇÕES CURRICULARES NACIONAIS E NO DOCUMENTO OFICIAL (PPP)
}

Referências à diversidade linguística e cultural são encontradas nas orientações curriculares nacionais assim como no Projeto Político Pedagógico (PPP) do Colégio Benjamin.

O Colégio Benjamin não coloca impedimento para manifestações culturais da comunidade russa, como no caso do uso de vestimentas características pelos alunos. As disputas e relações de poder, no entanto, podem implicar exclusões dos estudantes em estudo por conta do que podemos chamar, junto com Kleiman de um "autoritarismo homogeneizador de instituições" (KLEIMAN, 1998, p. 270). Tal autoritarismo, segundo a autora, age na contramão do reconhecimento da "identidade linguístico-cultural do aluno", fazendo com que instituições prefiram "ignorar a diferença e a pluralidade de culturas" (KLEIMAN, 1998, p. 270).

No entanto, nos excertos do Projeto Político-Pedagógico (PPP) do Colégio Benjamin e de documentos curriculares oficiais, encontramos exemplos de intenções e preocupações relativas à preservação da diversidade linguística e cultural. Enfatizando a importância da reflexão conjunta de todos os que compõem a comunidade escolar, o PPP propõe atividades para o conhecimento das especificidades e cultura de grupos minoritários (CAMPOS, 2015). Conforme estipulado já nas primeiras páginas desse documento, é compromisso da instituição levar em conta os interesses e as necessidades dos alunos. Nessa perspectiva, o Colégio é definido como um:

\begin{abstract}
a) lugar para a transformação de pessoas que dela participam; b) espaço democrático; c) espaço de participação ampla de toda comunidade escolar; d) lugar em que a educação é entendida como prática social; e) espaço para construção de instrumentos que capacitem o aluno para um processo permanente de educação; f) espaço em que alunos são coautores do conhecimento. (PPP do Colégio Benjamin, 2011, p. 40).
\end{abstract}

Além de definir o espaço educacional como um espaço plural, o PPP traz aspectos da história que incluem a discussão das cultura afrodescendente, indígena e imigrante, presentes naquele região, e de temas como cidadania, cultura, sexualidade, educação ambiental, educação fiscal, violência, educação tributária, entre outros temas relacionados aos direitos e deveres do corpo docente e discente da instituição. O PPP propõe ainda que a instituição escolar desenvolva atividades para o conhecimento das especificidades desses grupos, como, por exemplo, visitações nas comunidades russa e quilombola, com o objetivo de os alunos conhecerem as culturas dos grupos em questão (CAMPOS, 2015, p. 50). Segundo o documento, todos os alunos devem "sentir-se igualmente importantes no processo de ensino e aprendizagem" (PPP do Colégio Benjamin, 2011, p. 46).

$\mathrm{Na}$ mesma linha, o currículo de língua estrangeira do Colégio Benjamin, fundamentado em aspectos levantados nas Diretrizes Curriculares da Educação de Língua Estrangeira Moderna - DCE-LEM (PARANÁ, 2008) destaca o respeito à diversidade (cultural, identitária e linguística). 
Também em documentos de base nacional, o discurso institucional é colocado em favor da afirmação de diferentes identidades e culturas, conforme as Diretrizes Curriculares Nacionais pontuam:

\begin{abstract}
A diversidade econômica, social e cultural exige da escola o conhecimento da realidade em que vivem os alunos, pois a compreensão do seu universo cultural é imprescindível para que a ação pedagógica seja pertinente. Inserida em contextos diferentes, a proposta políticopedagógica das escolas deve estar articulada à realidade do seu alunado para que a comunidade escolar venha a conhecer melhor e valorizar a cultura local. Trata-se de uma condição importante para que os alunos possam se reconhecer como parte dessa cultura e construir identidades afirmativas, o que, também, pode levá-los a atuar sobre a sua realidade e transformá-la com base na maior compreensão que adquirem sobre ela. Ao mesmo tempo, a escola deverá propiciar aos alunos condições para transitarem em outras culturas, para que transcendam seu universo local e se tornem aptos a participar de diferentes esferas da vida social, econômica e política. (BRASIL, 2013, p.110).
\end{abstract}

Se o discurso nesses documentos oficiais é bastante genérico, localmente o trânsito entre culturas, no entanto, não é tão simples. Um exemplo da dificuldade do trânsito entre culturas na rotina escolar tem a ver com a necessidade de negociação com relação à merenda escolar: por terem hábitos alimentares restritos, os estudantes da colônia precisam levar para a escola seus próprios alimentos. Em uma conversa informal, uma mãe relata a dificuldade de seus filhos manterem a tradição (tanto em relação à religião, como em relação aos hábitos alimentares) dentro do ambiente escolar:

\footnotetext{
Eles não comem lanche na escola. Esses dias, eles [a escola] começaram a reclamar do lanche que eles [os alunos descendentes de russos] levam de casa... queriam proibir as crianças de levar. Eu perguntei para eles [para a escola]: E quando a quaresma começar? Vocês não respeitam a gente, vocês comem ovo:.... carne:.... dão de tudo [para os alunos]. Daí eles [escola] deixaram a gente continuar mandando o lanche de casa... A gente sempre tem que dar um jeito das nossas crianças levarem o lanche próprio de casa, até mesmo por causa da nossa religião! (DIÁRIO DE CAMPO, 28/01/2014).
}

O recuo da decisão da escola, diante do questionamento dessa mãe, fez com que os alunos descendentes de russos pudessem continuar levando seu lanche de casa.

\title{
3.3 REFERÊNCIAS À DIVERSIDADE NA FALA DA EQUIPE DIRETIVA E DOS PROFESSORES
}

No exemplo que segue, Maria, a professora de inglês, ao falar sobre como a escola lida com o modo de vestir dos alunos descendentes de russos, relata com contentamento, uma situação a que assistiu no pátio da escola:

\footnotetext{
Maria: Olha... eu já presenciei um dia em que alunos chegaram na escola com uma cordinha amarrada na altura da cintura para ficarem parecidos com os russos ((sorrindo)). E, quando os alunos russos olharam aquilo... todos deram risada... eu acho isso muito legal ((sorrindo)). Esse respeito com a diversidade acontece já nos primeiros contatos entre os alunos na sala de aula (DIÁRIO DE CAMPO, 29/04/2014).
} 
Para Maria, segundo o relato acima, o episódio é uma manifestação de respeito. Ela alegra-se por perceber a convivência, considerada por ela uma relação pacífica, de interesse e de preocupação com a cultura do outro. A celebração de Maria pode ser válida se consideramos a brincadeira performada por alunos brasileiros a partir da perspectiva de uma experiência de suspensão temporária de fronteiras étnicas (JAFFE, 2000; GARCEZ, 2016). Segundo essa perspectiva, uma quebra temporária dos limites lá estabelecidos teria a ver com a legitimação do capital cultural dos descendentes de russos. No entanto, diante das ideologias vigentes naquele microcenário, podemos dizer que a brincadeira é fundamentalmente ambígua, pois também pode conter traços da comédia que servem para reforçar estereótipos dominantes, "podendo variar de celebratórios para ofensivos" (GARCEZ, 2016, p. 99). Conforme explica Garcez, junto com Jaffe et al., 2015, a comédia, ao retirar uma experiência da realidade e da seriedade, pode contribuir para discursos de falta de legitimidade (GARCEZ, 2016).

Naquele tempo/espaço, dentro e fora de sala de aula, os alunos descendentes de russos têm também de lidar com discursos socialmente construídos acerca da descrição de suas experiências com línguas e nacionalidades. Conforme mostramos no relato a seguir, em um momento de formação continuada, os professores e agentes educacionais do Colégio Benjamin discutem questões relacionadas ao ensino das relações étnicoraciais, da história e cultura afro-brasileira e africana, e da história e cultura indígenas. Em pauta, questões relacionadas à cultura de grupos minoritários. Na cena descrita, Rodrigo, o secretário do Colégio Benjamin, compara os aspectos que vêm sendo discutidos sobre esse tema com a situação dos imigrantes:

\begin{abstract}
A discussão se desenvolvia de modo bastante consensual até o momento em que foram colocados em evidência assuntos relativos à diversidade cultural, quando a reunião tornouse mais tensionada. $\mathrm{O}$ grupo responsável por introduzir a temática iniciou a discussão sobre educação indígena e tentou, em linhas gerais, exemplificar a importância de se trabalhar esse assunto em sala de aula de forma transdisciplinar. A professora Isabela relatou sua experiência com grupos indígenas e se posicionou contrária ao fato de as mulheres desses grupos com os quais trabalhou serem as responsáveis pela venda de artesanato, enquanto os homens permaneciam na aldeia. Diante da exposição de Isabela sobre costumes culturais, Rodrigo comentou: "É igual os russos que querem ser russos e estão aqui. Se eles se acham russos, que voltem para a Rússia. Eles não comem a mesma comida porque se acham superior... Aí não querem se nivelar”. (DIÁRIO DE CAMPO, 24/06/2014).
\end{abstract}

Por outro lado, Caio, que é também professor, contesta:

\begin{abstract}
é preciso desmontar esta crença de uma identidade permanente, as características físicas, preto, branco, latino... Isso não pode prejudicar o outro. Não importam as diferenças, todos devem ser tratados com igualdade. Devemos ter a sensibilidade de nos colocar no lugar do outro. Estas divisões foram criadas pelos homens. Devemos olhar para todos como seres humanos" (DIÁRIO DE CAMPO, 24/06/2014).
\end{abstract}

Meses depois, em outro momento de formação continuada, a discussão sobre diversidade continua. No próximo exemplo, mostramos a fala de Guilherme, um dos professores presentes, que ao referir-se à cultura do grupo de descendentes de russos, argumenta: 
[...] eles não pensam como a gente, mas se acham muito superiores a nós, por isso não se misturam! Por que toda essa necessidade de mostrar que não são como nós? Isso é evidente: Eles falam "não somos como vocês" [...]. Na verdade todo esse tipo de grupo [...] no começo, quando eles vêm para pegar a terra, em vez de eles se abrirem, na questão das tradições [...] da religião, na verdade eles são presos por esses laços... (DIÁRIO DE CAMPO, 29/10/2014).

Diante desta colocação de Guilherme, sua colega, Aline, não concordando com o que ouviu, pondera: "Eles só fazem isso para preservar a cultura" (CAMPOS, 2015, p. 94).

Conforme se pode depreender dos exemplos acima, a diversidade cultural e linguística vem sendo vista pelos agentes institucionais não apenas sob uma perspectiva monolítica e essencializante de língua e cultura. Sendo assim, se por um lado, as identidades continuam sendo essencializadas, por outro elas também vêm sendo problematizadas e complexificadas no contexto escolar aqui focalizado.

\subsection{REFERÊNCIAS À DIVERSIDADE NA FALA DOS ALUNOS}

Consoante Jaffe (2011), as práticas de linguagem em contexto escolar geralmente são "moldadas pela natureza da escola como uma instituição conservadora que tradicionalmente valida apenas uma resposta correta, uma forma oficial da língua, um único código legítimo, uma única forma de conhecimento" (JAFFE, 2011, p. 215). Evidenciando o que essa autora chama de "posicionamento metassociolinguístico" (JAFFE, 2009, p. 120), os alunos descendentes de russos reproduzem em suas falas a distribuição imposta pela escola entre o russo e o português. Pedro e Leonardo ${ }^{7}$, por exemplo, falam russo e português, e Leonardo fala também o espanhol. Compartilham suas vivências e práticas culturais fora da escola em russo, que é a língua utilizada nas relações interpessoais na colônia e entendida como a língua das relações familiares. Em grupos de WhatsApp dos quais participam, interagindo com outros descendentes de russos que moram em países como Uruguai, Bolívia, Estados Unidos, Canadá, por exemplo, Pedro e Leonardo assim se referem ao uso que fazem dessas duas línguas:

Pedro: Eu uso o russo para conversar... e nas redes sociais... com os amigos e TUDO! O português... só na escola... (ENTREVISTA, 25/11/2014).

Leonardo: Português eu só uso na escola e na cidade; o russo, para todas as outras coisas (ENTREVISTA, 16/10/2014).

Em outro momento da conversa, porém, ao serem questionados sobre a possível mistura das línguas, Pedro enfatiza:

Pedro: Sim, isso acontece na maioria das vezes. Falamos tudo misturado. Nesse grupo de Whats app que falei, a gente fica fazendo bagunça e falando um monte de coisa, misturado. Usamos uma palavra em cada língua (ENTREVISTA, 25/10/2014).

\footnotetext{
${ }^{7}$ A fim de se preservar a identidade dos informantes, todos os nomes foram substituídos por pseudônimos. 
Eles, portanto, aprendem a lidar com o discurso legitimado da língua nacional, que o português é a língua da escola, é a língua 'que importa', mas o russo continua sendo utilizado como a língua da família, dos amigos, das redes sociais, da igreja. O posicionamento metassociolinguístico dos alunos descendentes de russos demonstra que eles entendem a projeção da instituição em relação ao uso da linguagem e a obrigatoriedade de aprender a língua majoritária do país (v. MAHER, 2007), mas procuram, no entanto, mecanismos de lidar com as fronteiras linguísticas, hegemonicamente estabelecidas, de modo a tomar decisões e liberdades em relação ao uso de seu repertório linguístico, sempre que estão fora da escola. Como destacam Garcia e Li Wei, ecoando Gumperz (1964), eles seguem, nesse sentido, "uma etiqueta social de escolhas de línguas" (GARCIA; LI WEI, 2014, p. 138). A liberdade deles está relacionada aos limites sociais e linguísticos naquele cenário. Assim sendo, estudantes como Pedro e Leonardo usam a língua russa (na medida em que criam espaços), para que os seus repertórios possam ser acionados e para que seus valores e práticas possam coexistir, fazendo com que diferentes aspectos de suas vidas, suas crenças e experiências possam ser vividas e experienciadas multiculturalmente (GARCIA; LI WEI, 2014).

No espaço da sala de aula, porém, o uso dos recursos linguísticos híbridos, segundo os participantes, pode não ser considerado adequado. Conforme observamos na fala de Samanta, abaixo transcrita, podemos dizer que ser multilíngue naquele cenário pode não significar qualquer "saliência social" (JAFFE, 2016) e tampouco estabelecer um posicionamento privilegiado do falante em relação aos interlocutores. Como destaca Jaffe, "a escola é representada como um campo de provas ideologicamente neutro para valores auto-evidentes e orientações comuns" (JAFFE, 2001, p. 294), onde sujeitos sociais que não se enquadram no padrão idealizado na instituição precisam enquadrar-se nos padrões estabelecidos da língua dominante.

A aluna Samantha explica os modos de lidar com a ordem social instituída na sala de aula. Samantha nasceu nos Estados Unidos e fala russo, inglês, português, espanhol e sabe um pouco de francês, língua que usa com seu irmão. Sua mãe é brasileira de ascendência russa. Seu pai é uruguaio e é também descendente de russos. Muito tímida, Samantha, nos períodos de recreio, geralmente fica no pátio do colégio com duas amigas que são da comunidade quilombola. Ao longo das aulas, mantém-se sempre em silêncio e, quando termina as atividades propostas em sala, apanha um livro de sua mochila e inicia sua leitura (NOTA DE CAMPO, 13/05/2014). A aluna fala, na entrevista, sobre suas dificuldades de interação no Colégio Benjamin e como ela, com a ajuda de seu colega de classe, também descendente russo, achou formas alternativas para participar dos momentos de aula, uma vez que chegou na escola sem saber português:

\footnotetext{
Samantha: No começo... tive ajuda de professores ... e de um russo... que fazia a tradução das aulas pra mim. Só assim para entender. A professora falava em português... e o russo falava pra mim em russo... Foi bem difícil... (ENTREVISTA, 25/06/2014).
}

E, ao falar sobre suas práticas de linguagem, ela diz:

\footnotetext{
Samantha: Eu acho o inglês fácil porque eu sei:: ... Quando cheguei aqui achei o português muito DIFÍCIL! ... Mas aprendi muitas coisas aprendendo o português. Eu prefiro o inglês ... Ah... na verdade, se eu tivesse com quem falar em espanhol seria melhor ((sorrindo)) (ENTREVISTA, 25/06/2014)
} 
As falas de Samantha ajudam a ilustrar o modo como as dinâmicas da escola com minorias etnolinguísticas podem ser diferentemente apreendidas, conforme a situação e os interlocutores. No caso de Samantha, as dificuldades não impediram sua inclusão em atividades de sala de aula.

Para os que nasceram no Brasil, surge a questão da identidade nacional. Quando perguntado sobre o assunto, Pedro, por exemplo, reafirma sua identidade linguística e cultural russa:

Pedro: Russo e brasileiro, os dois... Eu nasci no Brasil, mas sou russo. (ENTREVISTA, $25 / 11 / 2014)$

E enquanto Pedro mostra-se seguro quanto à sua identidade linguística e cultural, Juliana transita entre as identidades brasileira e russa:

Juliana: Eu me considero assim, nascida no Brasil, então brasileira. Se eu for assistir um jogo de futebol... entre Rússia:: e:: Brasil... eu ia torcer para o Brasil ((sorrindo)), mas a minha nacionalidade assim é:: um pouco diferente... por ser russa! (ENTREVISTA,16/10/2014).

Por fim, para Camila, a questão não é simplesmente um caso de duplicidade mas de mistura, ou como poderíamos dizer, de criação de um espaço em que as fronteiras não são nítidas.

Camila: “A gente é tudo misturado, né?”(ENTREVISTA, 24/01/2014)

As palavras de Camila desafiam o posicionamento de Pedro e também desafia toda categorização estanque e estratificação hierarquizada que sustenta os processos locais de exclusão.

\section{CONSIDERAÇÕES FINAIS}

Neste estudo, a investigação etnográfica possibilitou a discussão sobre o modo como alunos descendentes de russos fazem suas vidas, negociam, resistem e (re)criam significados em seu mundo multilíngue e multicultural, negociando identidades linguístico-culturas no espaço escolar.

Naquela localidade, em que a identidade russa não foi transformada em um bem de consumo, embora os descendentes de russos tenham um alto grau de autenticidade, seus recursos linguísticos e culturais parecem não contar para uma economia globalizada (HELLER, 2003). Na política e economia locais, a identificação da comunidade de russos como conservadora e atrasada, em termos de hábitos e costumes, não contribui para que a colônia seja considerada uma "zona particular de transformação" (HELLER, 2003, p. 473).

No cenário escolar, porém, diferentes perspectivas aparecem. Professores, alunos e equipe diretiva posicionam-se de modos diferentes em relação às fronteiras linguísticas que ora são reafirmadas, ora são flexibilizadas. Dependendo da situação e do interlocutor, essas fronteiras tornam-se mais ou menos visíveis o que nos levou a identificar um processo sociopolítico de inclusão que está em andamento naquele contexto específico. 
Nesse sentido, a escola se constitui como um espaço em que os participantes aprendem a criar dinâmicas de resistência e de agência. Diante da política escolar, os jovens descendentes de russos dedicam-se a aprender português sem, no entanto, abrir mão de seus recursos linguístico-culturais múltiplos em suas práticas cotidianas. Apontamos, no entanto, para a necessidade de futuras pesquisas etnográficas, envolvendo a comunidade como um todo, ou seja, para além do contexto escolar.

\section{REFERÊNCIAS}

BLOMMAERT, J. The sociolinguistics of globalization. Cambridge: Cambridge University Press, 2010. BRASIL. Diretrizes curriculares nacionais gerais da educação básica. Brasília: MEC / SEB / DICEI. 2013.

CAMPOS, B. Colisão de identidades, culturas e linguagem: um estudo etnográfico em uma comunidade de descendentes de russos. 2015. 171 p. Dissertação (Mestrado em Linguística) - Programa de PósGraduação em Linguística, Universidade Federal de Santa Catarina, Florianópolis, 2015.

DALLA VECHIA, A. Participação e usos de línguas em aulas de alemão em uma comunidade de suábios no sul do Brasil. 2018. 223f. Tese (Doutorado em Letras) - Universidade Estadual de Maringá, Maringá, 2018.

ERICKSON, F. Qualitative methods. In: LINN, R.L.; ERICKSON, F. (Eds.). Research in teaching and learning. v. 2. New York: Macmillan Publishing Company, 1990. p. 75-200.

FRITZEN, M. P.; NAZARO, A. C.; RIVES, R. Usos da língua alemã em duas localidades de Blumenau, SC: "É legal, eu gosto de falar com a minha oma". Estudos literários, n. 50, p. 83-99, 2014.

GARCEZ, P.; SCHULZ, L. Olhares circunstanciados: etnografia da linguagem e pesquisa em Linguística Aplicada no Brasil. D.E.L.T.A, v. 31, n. Especial, p. 1-34, 2015.

GARCEZ, P. M. Ventilando identidades étnicas e linguísticas por meio de atuações cômicas públicas na mídia: desafio e reforço a ideologias normativas. Revista da Anpoll, v. 1, n. 40, p. 90-100, 2016.

GARCÍA, O. Bilingual education in the $21^{\text {st }}$ century: a global perspective. Malden, MA/Oxford: Basil/Blackwell. 2009.

GARCÍA, O; WEI, Li. Translanguaging: language, bilingualism and education. London: Palgrave, 2014. HELLER, M. Globalization, the new economy, and the commodification of language and identity.

Journal of Sociolinguistics, v. 7, n. 4, p. 473- 492, 2003.

HYMES, D. Ethnography, linguistics, narrative inequality: towards an understanding of voice. London: Taylor \& Francis, 1996.

JAFFE, A. Authority and authenticity: Corsican discourse on bilingual education. In: HELLWE, M.; MARTIN-JONES, M. (Eds.). Voices of authority: education and linguistic difference. Westport: ABLEX, 2001, p. 269-296.

Critical perspectives on language-in-education policy: the Corsican example. In: McCarty, T.

(Ed.). Ethnography and language policy. London: Routledge, 2011. p. 205-230. Introduction. In: JAFFE, A. (Ed.). Stance: sociolinguistic perspectives. Oxford: Oxford University Press, 2009, p. 1-28. 2000. Comic performance and the articulation of hybrid identity. Pragmatics, v. 10, n. 1, p. 39-59,

Indexicality, stance and fields in sociolinguistics. 2016. Disponível em:

<https://www.cambridge.org/core/books/sociolinguistics/indexicality-stance-and-fields-insociolinguistics/CD68827F765CAA1EE5714D5264DDFE9D>. Acesso em: abr. 2018.

KLEIMAN, A. A construção de identidades em sala de aula: um enfoque interacional. In: SIGNORINI, I. (Org.). Linguagem e identidade: elementos para uma discussão no campo aplicado. Mercado de Letras: São Paulo, 1998. p. 267-302.

LUCENA, M. I. P. Práticas de linguagem na realidade da sala de aula: contribuições da pesquisa de cunho etnográfico em Linguística Aplicada. D.E.L.T.A, v. 31, n. Especial, p. 67-95, 2015.

MAHER, T. M. A Educação do entorno para a interculturalidade e o plurilinguismo. In: KLEIMAN, A.; CAVALCANTI, M. (Org.). Linguística Aplicada: suas faces e interfaces. Campinas: Mercado de Letras, 2007. p. 255-270.

LUCENA, Maria Inêz Probst; CAMPOS, Bianca. Dinâmicas sociolinguísticas e culturais de inclusão/exclusão de alunos descendentes de imigrantes russos no sul do Brasil. Linguagem em (Dis)curso - LemD, Tubarão, SC, v. 18, n. 3, p. 715-728, set./dez. 2018. 
MURÁ, A. G. Russos vivem como no século 19 em Ponta Grossa. 6 dez. 2016. Disponível em: <http://www.aroldomura.com.br/?p=9830>. Acesso em: 20 maio 2018.

PARANÁ. Secretaria de Estado da Educação. Diretrizes curriculares de língua estrangeira moderna. S. 1.: Secretaria de Estado da Educação da Paraná, 2008.

RAMPTON, B. et al. UK Linguistic Ethngoraphy: a discussion paper. 2004. Disponível em:<http://www.lancaster.ac.uk/fss/organisations/lingethn/documents/discussion_paper_jan_05.pdf.> Acesso em: 12 mar. 2018.

SIGNORINI, I. Metapragmáticas da língua em uso: unidades e níveis de análise. In: (Org.). Situar a linguagem. São Paulo: Parábola, 2008. p. 117- 148.

WALDMANN, I. M. Fazenda Santa Cruz dos Campos Gerais e a imigração russa (1792- 1990). Ponta Grossa: Planeta, 1992.

WANG et al. Globalization in the margins: toward a re-evaluation of language and mobility. Applied Linguistics Review, v. 5, n. 1, p. 23-44, 2014. Disponível em:

<http://www.academia.edu/attachments/33479641/download>. Acesso em: 5 maio 2018.

\section{Recebido em: 15/08/18. Aprovado em: 24/09/18.}

Title: Sociocultural dynamics of inclusion/exclusion of Russian descendent students in Southern Brazil

Authors: Maria Inêz Probst Lucena; Bianca Campos

Abstract: Drawing on school ethnography, based on data generated from participant observation, interviews, field diaries and documental analysis, this study focus on the way Russian descendent students in Southern Brazil deal with linguistic borders and sociocultural dynamics of inclusion/exclusion at school. Our main goal is to show how linguistic and sociocultural borders are enacted by participants in their speech. Data analysis shows that different perspectives appear. Teachers, students and school staff vary their opinions and sometimes they appear to be stricter and sometimes more lenient regarding linguistic and sociocultural borders. Depending on the situation and interlocutor, such borders may become more or less visible, what points to a developing sociopolitical process of inclusion in that specific context.

Keywords: Multilingualism. Linguistic borders. Cultural borders. Russian immigrants. Minority groups.

Título: Dinámicas sociolingüísticas y culturales de inclusión/exclusión de alumnos descendentes de inmigrantes rusos en sur de Brasil

Autores: Maria Inêz Probst Lucena; Bianca Campos

Resumen: Desde una etnografía escolar basada en datos generados de observación participante, entrevistas, diarios de campo y análisis documental, este estudio enfoca en el modo como los alumnos descendentes de inmigrantes rusos de una ciudad del sur de Brasil hacen frente con fronteras lingüísticas y dinámicas socioculturales de inclusión/exclusión en la escuela. Lo principal objetivo es demostrar como fronteras lingüísticas y socioculturales aparecen en las hablas de los participantes en escenario escolar. El análisis de los datos muestra que diferentes perspectivas aparecen. Profesores, alumnos y equipe directiva se posicionan de modos diferentes en relación con las fronteras que son reafirmadas o flexibilizadas. Dependiendo de la situación y del interlocutor, tales fronteras pueden se cambiar más o menos visibles, apuntando para un proceso sociopolítico de inclusión en desarrollo en aquel contexto específico.

Palabras clave: Multilingüismo. Fronteras lingüísticas. Fronteras culturales. Inmigrantes rusos. Minorías.

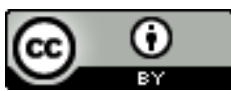

Este texto está licenciado com uma Licença Creative Commons Atribuição 4.0 Internacional.

LUCENA, Maria Inêz Probst; CAMPOS, Bianca. Dinâmicas sociolinguísticas e culturais de inclusão/exclusão de alunos descendentes de imigrantes russos no sul do Brasil. Linguagem em (Dis)curso - LemD, Tubarão, SC, v. 18, n. 3, p. 715-728, set./dez. 2018. 